\title{
BMJ open Myocardial function in premature infants: a longitudinal observational study
}

\author{
Beate Horsberg Eriksen, ${ }^{1,2}$ Eirik Nestaas, ${ }^{3}$ Torstein Hole, ${ }^{4,5}$ Knut Liestøl, ${ }^{6}$ \\ Asbjørn Støylen, ${ }^{2,7}$ Drude Fugelseth ${ }^{8,9}$
}

To cite: Eriksen $\mathrm{BH}$, Nestaas E, Hole T, et al. Myocardial function in premature infants: a longitudinal observational study. BMJ Open 2013;3: e002441. doi:10.1136/ bmjopen-2012-002441

- Prepublication history for this paper are available online. To view these files please visit the journal online (http://dx.doi.org/10.1136/ bmjopen-2012-002441).

Received 4 December 2012 Revised 1 March 2013 Accepted 4 March 2013

This final article is available for use under the terms of the Creative Commons Attribution Non-Commercial 2.0 Licence; see http://bmjopen.bmj.com

For numbered affiliations see end of article.

\section{Correspondence to} Dr Beate Horsberg Eriksen; beate.h.eriksen@ntnu.no

\section{ABSTRACT}

Objectives: Gestational and chronological age may have an impact on myocardial function. We studied the longitudinal changes of the atrioventricular tissue Doppler velocities in premature infants through the neonatal transitional period and at expected term and explored the reproducibility of the measurements.

Design: Prospective, observational and longitudinal cohort study.

Setting: Two-centre study, from a secondary and a tertiary neonatal intensive care unit.

Participants: 55 infants (29 males) with gestational age 31-35 weeks and birth weight 1127-2836 grams.

Primary and secondary outcome measures:

Pulsed-wave atrioventricular left, septum and right ventricular annulus tissue Doppler systolic ( $\left.S^{\prime}\right)$, early diastolic $\left(E^{\prime}\right)$ and late diastolic $\left(A^{\prime}\right)$ velocities measured by repeated echocardiographic examinations days 1, 2 and 3 and at expected term.

Results: All velocities increased significantly from the neonatal period to expected term $(p<0.001)$. We found a significant correlation between gestational age and rightsided $S^{\prime}, E^{\prime}$ and $A^{\prime}$ on day 1 (Pearson correlation 0.32$0.46, p<0.05)$, for $S^{\prime}$ in all three walls and septal $E^{\prime}$ and $A^{\prime}$ on day 2 (Pearson correlation 0.27-0.49, $p<0.05$ ). There was a moderate linear correlation between left ventricle end-diastolic length and septal and right $\mathrm{S}^{\prime}$ at term and for septal $E^{\prime}$ and $A^{\prime}$ at day 1 (Pearson correlation $0.30-0.56, p<0.05$ ). We found no correlation between heart rate and tissue Doppler velocities when controlling for the effect of fusion. Continuous positive airway pressure showed moderate effect where as persistence of the ductus arteriosus showed no effect on the tissue Doppler velocities. The $E^{\prime} / A^{\prime}$ relationship was consistently reversed throughout the study with frequently fused diastolic tissue velocity signals.

Conclusions: Pulsed-wave atrioventricular annulus tissue Doppler velocities were related to gestational age, postnatal age and ventricular size. Right ventricle velocities showed more pronounced increase with postnatal maturation than left ventricle velocities. The degree of $E^{\prime} / A^{\prime}$ fusion influenced the diastolic tissue Doppler velocities and should be reported if present.

\section{INTRODUCTION}

Complex cardiorespiratory changes take place during transition from intrauterine to

\section{ARTICLE SUMMARY}

Article focus

- Tissue Doppler velocities of the atrioventricular annulus can be used as a marker of global myocardial function.

- Moderately premature infants have received little attention in echocardiographic studies.

- In this longitudinal study we assessed the dynamic changes in myocardial function by cardiac tissue Doppler velocities through the newborn transitional circulation and at expected term in moderately preterm infants.

Key messages

- Gestational age, postnatal age and ventricular size all influenced myocardial function measured by pulsed wave tissue Doppler imaging velocities.

- All cardiac tissue Doppler velocities increased significantly from the neonatal period to expected term with a more pronounced increase in right ventricle velocities compared to the left side. Results were higher than in healthy term infants from previous studies.

- The degree of early and late diastolic wave fusion influence diastolic tissue Doppler velocities and should be reported if present.

Strengths and limitations of this study

- The strength of this study is the serial design with four repeated examinations for each participant. This takes into account the dynamic changes with age and maturation and differentiates the study from previous ones.

- Limitations include the incompleteness in the number of analyses. This is because of both drop outs at follow-up and poor image quality in some cases. Image quality was sometimes suboptimal as reflected in the intravariability and the intervariability analyses. The infants were not sedated and some of them were agitated or cried through parts of the examinations, especially during the term examinations. This reflects the difficulties in examining noncooperative patients, but is also caused by inevitable biologic variation because of respiration and natural movement. Also, postnatal adaptive changes might already have occurred prior to the first examination. A study designed with the first examination within few hours after birth followed by several repeated examinations just a few hours apart would have been more appropriate to detect the very early postnatal changes in TDI velocities. 
extrauterine life. At birth the rapid decrease in pulmonary vascular resistance and the increase of pulmonary blood flow increase preload to the left side of the heart. The systemic vascular resistance increases with disconnection of the placenta. During the following days and weeks, the loading conditions of the left and right ventricles further change with closure of the fetal shunts and structural changes in the smooth vasculature of the pulmonary vessels. ${ }^{12}$

Premature infants are especially vulnerable to haemodynamic instability, and the haemodynamic changes through fetal-neonatal transition are not completely understood. Clinical assessment of cardiovascular status is unreliable in neonates. ${ }^{3-6}$ Conventional echocardiography is widely applied for haemodynamic assessment. ${ }^{7}$ Ventricular function, examined by conventional echocardiography has mainly focused on visual judgements and indirect indices such as fractional shortening of the left ventricle and recordings of blood velocities. Tissue Doppler imaging (TDI) focuses on the ventricular wall motion and allows for measurement of regional and global myocardial function. ${ }^{8}$ Both systolic and diastolic function can be assessed simultaneously by this method, enabling a more comprehensive evaluation. The velocity of longitudinal atrioventricular annulus motion can be used as a marker of global myocardial function. ${ }^{8}$ TDI is increasingly used to assess ventricular function in adults, ${ }^{10}{ }^{11}$ and there are several cross-sectional studies reporting feasibility applying TDI in neonates and children. ${ }^{12-18}$ However, studies in moderately preterm infants are scarce and usually include few participants. Premature birth is an adverse event that can disturb the normal cardiovascular physiology. The dynamic changes during the fetal-neonatal transition may show different echocardiographic results in preterm than in term infants. The aim of this study was to first explore the atrioventricular annulus TDI velocities in premature infants during the postnatal cardiovascular transitional period and to compare these with the results at expected term. Second, we wanted to assess the reproducibility of the measurements.

\section{METHODS}

\section{Setting and study population}

A two-centre, prospective cohort study was performed. All premature infants born at the gestational age of 31-35 weeks without major congenital malformations, sepsis or need of cardiovascular supportive treatment were included from the Neonatal Intensive Care Unit at the Department of Paediatrics, Ålesund Hospital $(n=40)$ and the Department of Neonatal Intensive Care, Oslo University Hospital, Ullevål $(\mathrm{n}=15)$ between March 2010 and December 2011, whenever personnel and equipment were available. Based on previous studies, ${ }^{12}$ inclusion of 48 infants would provide a statistical power of $80 \%$ for detecting a $10 \%$ difference between days with a $\mathrm{p}$ value of $5 \%$.

\section{Echocardiographic examinations}

Transthoracic echocardiography was performed daily during the first 3 days of life and at expected term $( \pm 14$ days) by two investigators (BHE, DF) using Vivid i and Vivid S6 ultrasound devices (GE Vingmed, Horten, Norway) with standard phase array multifrequency transducers (7S probe; $3.5-8 \mathrm{MHz}$ and $5 \mathrm{~S}$ probe; 2.0 $5.0 \mathrm{MHz}$ ). Structural abnormality was excluded at the first examination. Pulsed wave ( $\mathrm{pw}$ ) TDI atrioventricular annulus velocities were obtained from the apical fourchamber view. The sample volume $(5 \mathrm{~mm}$; default setting) was placed at the lateral and septal attachments of the mitral valve (left lateral wall and septum) and at the lateral attachment of the tricuspid valve (right lateral wall) with the annular plane motion parallel to the ultrasound beam. We used default frame rate, tissue velocity range of $\pm 16 \mathrm{~cm} / \mathrm{s}$ and simultaneous good-quality ECG signal. Three to five consecutive cardiac cycles were recorded for each view.

\section{Off-line analyses}

All images were analysed offline by one observer (BHE) using the manufacturer's software (EchoPac PC V.108.1.5, SW, GE Vingmed, Horten, Norway). Standard echocardiographic measurements were performed according to guideline recommendations. ${ }^{7}$ Gain was reduced to measure peak signals in the left and right walls and septum. The positive systolic peak $\left(S^{\prime}\right)$ is the peak annular motion towards the apex. The two negative diastolic peaks are the peak annular motions away from the apex during early ventricular relaxation $\left(\mathrm{E}^{\prime}\right)$ and atrial contraction ( $\mathrm{A}^{\prime}$; figure 1$)$. Whenever total fusion of $\mathrm{E}^{\prime}$ and $\mathrm{A}^{\prime}$ occurred, no diastolic velocity was measured. Both $\mathrm{E}^{\prime}$ and $\mathrm{A}^{\prime}$ were measured when an $\mathrm{E}^{\prime}$ wave could be recognised as a defined velocity peak when partial fusion occurred. Left ventricular end-diastolic length (LVEDL) was measured in B-mode four-chamber

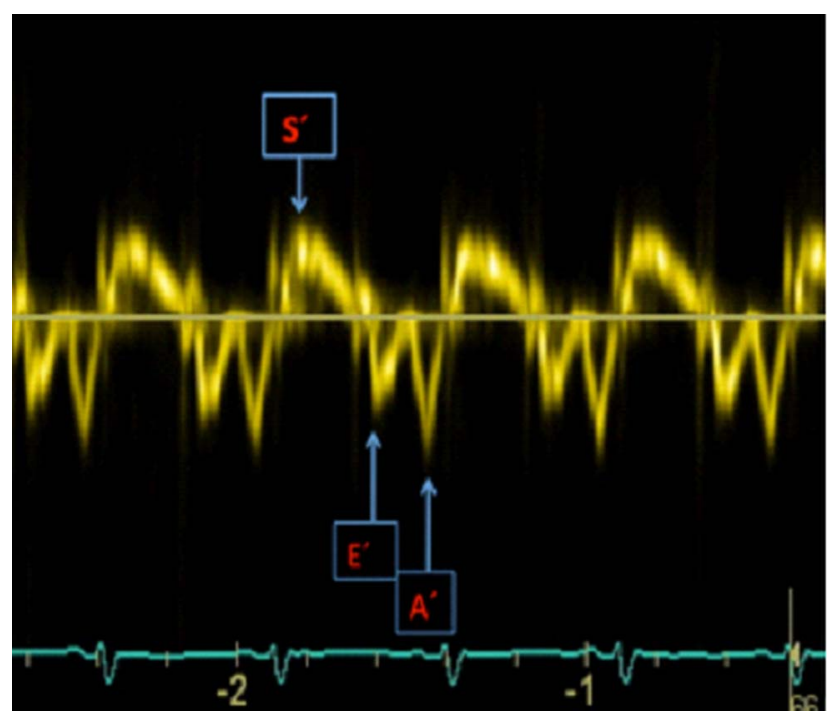

Figure 1 Pulsed-wave tissue Doppler velocity, septal recording. $S^{\prime}$, peak systolic velocity; $E^{\prime}$, peak early diastolic velocity; $A^{\prime}$, peak late diastolic velocity. 
view from the apical epicardium to the sepal attachment of the mitral valve. Heart rate (HR) was obtained from the mitral Doppler flow signals. All variables were averaged from three cardiac cycles.

\section{Statistics}

Statistical analyses were performed using SPSS for Windows, V.18.0 (SPSS Inc, Chicago, Illinois, USA) or JMP V.9.0 (SAS Institute). The tissue Doppler variables showed no marked outliers, and paired t tests were used to test differences between successive days. Depending on the data distribution, the Pearson or Spearman r correlation coefficient was used to assess correlation between variables. General linear models were used to investigate possible confounding factors. Two-sided $\mathrm{p}$ values $<0.05$ were considered statistically significant.

To assess offline interobserver measurement variability, two experienced observers (BHE, TH) carried out a blinded analysis of 20 randomly selected cases. Intraobserver variability was evaluated by repeated measurements several months apart by the main investigator (BHE). All the tissue Doppler variables were selected for Bland-Altman ${ }^{19}$ reproducibility analyses. Variability between measurements was computed as the difference between two measurements expressed as a percentage of the mean of the two measurements. The repeatability coefficient is defined as two times the SD of the difference between the measurements.

\section{Ethical considerations}

The study was approved by the Scientific Committees in both hospitals and by the Regional Committee for Medical and Health Research Ethics. Informed parental consent was obtained.

\section{RESULTS}

\section{Study population}

Patient characteristics are shown in table 1.

Fifty-five premature infants were included and examined at median (range) postnatal age 13 (2-21), 38 (26-48) and 64 (54-72) h. The term examinations were conducted at $40^{+1}\left(38^{+2}-42^{+6}\right)$ weeks $^{\text {+days }}$. The need for respiratory support is depicted in table 2.

One infant was excluded after the second examination because of pericardial effusion and left-sided pneumothorax that complicated echocardiographic examination. A set of triplets were moved to another hospital after the second examination. Three other infants were for various reasons lost to follow-up at term. Additional missing data are because of either missing images or images not eligible for analysis.

\section{Conventional echocardiographic data}

All infants had structurally normal hearts except for three infants with small, restrictive, muscular ventricular septal defects.

There are several methods to assess the haemodynamic significance of the ductus arteriosus, with ductal size

\begin{tabular}{|c|c|}
\hline Characteristics & \\
\hline Gestational age $\left(\right.$ weeks $\left.^{+ \text {days } *}\right)$ & $33^{+5}\left(31-34^{+6}\right)$ \\
\hline Birth weight $\left(g^{\star}\right)$ & $1900(1127-2836)$ \\
\hline Body weight, expected term $\left(\mathrm{g}^{*}\right)$ & $3195(2330-4540)$ \\
\hline Males, $n$ (\% of all) & $29(53)$ \\
\hline SGA, $n$ (\% of all) & $19(35)$ \\
\hline Singletons $(n)$ & 33 \\
\hline Twins, $n$ (pairs) & $16(8)$ \\
\hline Triplets, $n$ (pairs) & $6(2)$ \\
\hline Apgar at $1 \mathrm{~min} \dagger$ & $7.9(1.6)$ \\
\hline Apgar at 5 mint & $8.1(1.0)$ \\
\hline Caesarean section (n) & 36 \\
\hline Surfactant therapy (n) & 3 \\
\hline Volume expansion & 2 \\
\hline $\begin{array}{l}\text { Prenatal maternal steroids, } \\
\mathrm{n}(\% \text { of total) }\end{array}$ & $39(71)$ \\
\hline PDA, n (days 1-2-3-expected term) & $46-22-9-2$ \\
\hline
\end{tabular}

being one of the most frequently used parameters. In this study the persistent ductus arteriosus (PDA) was considered haemodynamically important if the diameter measured from the colour Doppler signal was above $1.5 \mathrm{~mm}$, and this was found in 17, 7 and 2 infants during the first 3 days, respectively. Two infants had a small PDA without haemodynamic significance at expected term. Patent foramen ovale was present in 49,37 and 22 infants during the first 3 days and in 9 infants at expected term, all with minimal atrial shunting.

\section{Pulsed wave tissue Doppler velocities}

Table 3 shows $\mathrm{S}^{\prime}, \mathrm{E}^{\prime}$ and $\mathrm{A}^{\prime}$ for the left lateral, septal and right lateral walls at the level of atrioventricular annulus attachment.

The increase in tissue velocities from days 1 to 2 were significant for septal and right $\mathrm{S}^{\prime}$ and septal $\mathrm{A}^{\prime}(\mathrm{p}<0.05)$. From days 2 to 3 there was a significant increase in tissue velocities for left and septal $S^{\prime}(p<0.05)$, but otherwise a slight numeric decline for most parameters. A pronounced increase was observed for all parameters at expected term $(p<0.001)$. $A^{\prime}$ was higher than $E^{\prime}$ for all three ventricular walls throughout all examinations $(\mathrm{p}<0.001)$.

There were significant correlations between gestational age and right-sided $\mathrm{S}^{\prime}, \mathrm{E}^{\prime}$ and $\mathrm{A}^{\prime}$ on day 1 (Pearson correlation $0.32-0.46, \mathrm{p}<0.05)$. On day 3 the correlations were present for $\mathrm{S}^{\prime}$ for all three walls and for septal $\mathrm{E}^{\prime}$ and $\mathrm{A}^{\prime}$ on day 2 (Pearson correlation 0.27-0.49, $\mathrm{p}<0.05$ ). A moderate linear correlation was found between LVEDL and septal and right $\mathrm{S}^{\prime}$ at term and for septal $\mathrm{E}^{\prime}$ and $\mathrm{A}^{\prime}$ at day 1 (Pearson correlation $0.30-0.56, \mathrm{p}<0.05$ ). Univariate analysis of variance were used to assess the possible effects of CPAP-treatment, presence of PDA (yes/no and diameter $<1.5 \mathrm{~mm} /$ diameter $>1.5 \mathrm{~mm}$ ), oxygen supplementation and SGA on pwTDI velocities day 1. Results were 
Table 2 Need for respiratory support

\begin{tabular}{lcccc}
\hline & Day $\mathbf{1}(\mathbf{n}=\mathbf{5 5})$ & Day 2 $(\mathbf{n = 5 5 )}$ & Day 3 $(\mathbf{n = 5 1 )}$ & Term $(\mathbf{n = 4 8 )}$ \\
\hline Oxygen $>21 \%$ & $7(12.7)$ & $4(7.3)$ & $2(3.9)$ & 0 \\
nCPAP & $26(46)$ & $13(23)$ & $8(15)$ & 0 \\
Ventilator & 0 & $2(3.6)$ & $2(3.9)$ & 0 \\
\hline Data are given as number and percentage of total. & & & \\
nCPAP, nasal continuous positive airway pressure. & & &
\end{tabular}

significant in three out of 45 analyses; CPAP showed an effect on left $\mathrm{E}^{\prime}$ and right $\mathrm{A}^{\prime}$ velocities $(\mathrm{p}<0.05)$ and SGA showed effect on left $\mathrm{A}^{\prime}$ velocities $(\mathrm{p}<0.05)$. This indicates only a moderate effect of CPAP and SGA.

We also studied possible correlations between HR and tissue Doppler velocities. There were no correlations apart from left $\mathrm{A}^{\prime}$ at day 3 (Pearson correlation 0.38, $\mathrm{p}<0.05$ ) and septal $\mathrm{A}^{\prime}$ at expected term (Pearson correlation 0.40, $\mathrm{p}<0.05)$. This may reflect the tendency for fusion between $\mathrm{E}^{\prime}$ and $\mathrm{A}^{\prime}$ waves that will influence the measurement of the $\mathrm{A}^{\prime}$ wave as discussed previously. In fact, when controlling for the degree of fusion of $\mathrm{E}^{\prime}$ and $\mathrm{A}^{\prime}$ waves the correlation between the variables disappeared.

\section{Fusion of $\mathbf{E}^{\prime}$ and $\mathrm{A}^{\prime}$}

Total diastolic wave fusion of $\mathrm{E}^{\prime}$ and $\mathrm{A}^{\prime}$ was dominantly observed with HRs above $155-160 / \mathrm{min}$. There were significant correlations between HR and degree of fusion for all walls at day 1 and 2 (Spearman $\mathrm{r}$ 0.35-0.59, $\mathrm{p}<0.05$ ) and for the septum at day $3(0.33, \mathrm{p}<0.05)$. Fusion was more frequently observed at expected term for all three walls, and was more frequent in the right lateral wall than in the left lateral wall and septum (table 4).

\section{Reproducibility}

Bland-Altman plots of intraobserver and interobserver variability for the tissue Doppler variables revealed no marked association between variability and the tissue velocity (data not shown). The median (range) of the intraobserver variability over the nine pwTDI variables was $4.5(3.1-7.8) \%$, the median coefficient of repeatability $0.63(0.38-1.16) \mathrm{cm} / \mathrm{s}$ with the highest values found for $\mathrm{E}^{\prime}$ in the septum (to a large extent caused by one observation, table 4). There were no systematic differences between first and second measurements in the intraobserver analysis. Also, for the interobserver case, the systematic differences were small (all well below $0.2 \mathrm{~cm} / \mathrm{s}$ ), although still significant for the septal $S^{\prime}$ and the left $\mathrm{E}^{\prime}$. The median variability for the pwTDI variables were $5.3(1.9-9.8) \%$ and the median coefficient of repeatability $0.63(0.38-1.48) \mathrm{cm} / \mathrm{s}$ between the two observers (table 5 ).

\section{DISCUSSION}

Enhanced knowledge and understanding of the postnatal changes in myocardial function can improve cardiovascular treatment, and this study provides novel

Table 3 Systolic and diastolic annulus pulsed wave tissue Doppler velocities days 1-3 and at term

\begin{tabular}{|c|c|c|c|c|}
\hline & Day 1 & Day 2 & Day 3 & Expected term \\
\hline HR (bpm) & $142(15)$ & $144(13)$ & $143(15)$ & $163(15)^{\star \star *}$ \\
\hline LVEDL & $28.4(3.1)$ & $28.6(2.7)$ & $28.4(2.9)$ & $36.2(2.9)^{\star \star \star}$ \\
\hline \multicolumn{5}{|c|}{ Left lateral wall $(\mathrm{cm} / \mathrm{s})$} \\
\hline$S^{\prime}(n$ 45-52) & $3.75(0.90)$ & $3.89(0.76)$ & $4.04(0.98)^{\star}$ & $5.88(1.09)^{\star * \star}$ \\
\hline$E^{\prime}$ (n 39-49) & $5.06(1.12)$ & $5.40(1.45)$ & $5.27(1.23)$ & $7.84(1.38)^{\star * *}$ \\
\hline $\mathrm{A}^{\prime}$ (n 39-49) & $5.71(1.71)$ & 6.09 (1.64) & $5.88(1.88)$ & $9.78(2.53)^{\star \star *}$ \\
\hline \multicolumn{5}{|l|}{ Septum $(\mathrm{cm} / \mathrm{s})$} \\
\hline$S^{\prime}(n+45-52)$ & $3.50(0.62)$ & $3.73(0.67)^{\star}$ & $4.02(0.74)^{\star}$ & $5.54(1.05)^{\star \star \star}$ \\
\hline$\left.E^{\prime}(n) 33-48\right)$ & $4.18(0.88)$ & $4.46(1.07)$ & $4.48(0.79)$ & $6.89(1.08)^{\star \star \star}$ \\
\hline$A^{\prime}(n$ 33-48) & $5.86(1.44)$ & $6.40(1.45)^{\star}$ & $6.11(1.39)$ & $8.76(2.04)^{\star * *}$ \\
\hline \multicolumn{5}{|c|}{ Right lateral wall $(\mathrm{cm} / \mathrm{s})$} \\
\hline $\mathrm{S}^{\prime}(\mathrm{n} 45-51)$ & $5.30(1.00)$ & $5.77(1.07)^{\star \star}$ & $5.71(0.96)$ & $9.47(1.41)^{\star \star \star}$ \\
\hline$E^{\prime}$ (n 22-39) & $5.58(1.52)$ & $5.83(1.30)$ & $5.80(1.13)$ & $10.13(1.97)^{\star \star \star}$ \\
\hline$A^{\prime}(n$ 22-39) & $8.00(2.23)$ & $8.45(1.98)$ & $7.85(2.17)$ & $11.22(2.13)^{\star \star \star}$ \\
\hline
\end{tabular}

Values are mean (SD).

${ }^{*} p<0.05$ compared with that of previous day.

${ }^{* \star} p<0.01$ compared with that of previous day.

${ }^{* * *} \mathrm{p}<0.001$ compared with that of previous day (term with day 3 ).

$A^{\prime}$, peak late diastolic pulsed wave tissue Doppler velocity; $E^{\prime}$, peak early diastolic pulsed wave tissue Doppler velocity; HR, heart rate; LVEDL, left ventricular end-diastolic length; $n$, number of patients analysed on each examination; $\mathrm{S}^{\prime}$, peak systolic pulsed wave tissue Doppler velocity. 
Table 4 Total and partial fusion of $E^{\prime}$ and $A^{\prime}$ waves in the left lateral, septum and right lateral walls at days 1-3 and at term

\begin{tabular}{|c|c|c|c|c|c|c|c|c|}
\hline & \multicolumn{2}{|c|}{$\begin{array}{l}\text { Fusion day } 1 \\
(n=50)\end{array}$} & \multicolumn{2}{|c|}{$\begin{array}{l}\text { Fusion day } 2 \\
(n=51-52)\end{array}$} & \multicolumn{2}{|c|}{$\begin{array}{l}\text { Fusion day } 3 \\
(n=45)\end{array}$} & \multicolumn{2}{|c|}{$\begin{array}{l}\text { Fusion at term } \\
(n=43-44)\end{array}$} \\
\hline & Total & Partial & Total & Partial & $\overline{\text { Total }}$ & Partial & Total & Partial \\
\hline Fusion $E^{\prime}-A^{\prime}$ left lateral & 2 & 4 & 7 & 2 & 5 & 2 & 6 & 13 \\
\hline Fusion $E^{\prime}-A^{\prime}$ septum & 3 & 4 & 4 & 9 & 3 & 4 & 12 & 11 \\
\hline Fusion $E^{\prime}-A^{\prime}$ right lateral & 13 & 4 & 14 & 9 & 6 & 7 & 23 & 5 \\
\hline
\end{tabular}

Values are expressed as numbers of analyses.

$\mathrm{A}^{\prime}$, peak late diastolic pulsed wave tissue Doppler velocity; $\mathrm{E}^{\prime}$, peak early diastolic pulsed wave tissue Doppler velocity; $n$, number of available analyses on each examination.

insight into longitudinal changes in the myocardial function in premature infants through the transitional period and with maturation.

\section{Principal findings}

We have shown that the myocardial function measured by atrioventricular tissue Doppler velocities increased with postnatal age and were positively correlated to gestational age at birth. Even though the changes during the first 3 days were small, there was a clear trend of increasing velocities throughout the study period. Increased tissue Doppler velocities with increased gestational age at birth and increased postnatal age are in accordance with earlier studies in newborns. ${ }^{12} 1318$ This is further reflected by lower peak systolic velocities during the first 3 days in our group of moderately premature infants, compared to previous studies in term newborns, ${ }^{12} 13$ and also by higher velocities compared with studies in the very preterm neonates. ${ }^{13}$ Furthermore, we found higher pwTDI systolic and diastolic velocities at expected term compared with those from studies in term newborn infants. ${ }^{12} 20$ Although the fourth examination was done at expected term, this was several weeks after birth when the haemodynamic pressure changes and adaptive maturation of the myocardium have evolved. Unequal postnatal age can therefore explain some of these differences.

There is a close relationship between body size and the size of cardiovascular structures, ${ }^{7}$ and cardiac size has shown to be positively correlated to pwTDI velocities. ${ }^{18}$ Accordingly, we found a moderate correlation between LVEDL and septal $\mathrm{S}^{\prime}$ at expected term, for septal $\mathrm{E}^{\prime}$ at days 1 and 2 and for septal $\mathrm{A}^{\prime}$ at day 1 .

$\mathrm{S}^{\prime}$ was significantly higher in the right lateral wall than in the septum and left lateral wall at all four examinations $(p<0.001)$, as shown in earlier studies in newborn infants, ${ }^{12}{ }^{13}$ children $^{21}$ and adults. ${ }^{11}$ This difference was even more pronounced at expected term. Systolic tissue velocities are influenced by afterload as known from early experimental works ${ }^{22}$ and newer tissue Doppler studies $^{23}$ and the right-sided $S^{\prime}$ will thereby be influenced by the decrease in right-sided afterload that occurs during the first few weeks of life. ${ }^{1}$

HR at expected term was significantly higher than that during the first three examinations. However, we found no correlation with tissue Doppler velocities when controlling for the effect of fusion. Earlier studies report conflicting correlations between tissue Doppler velocities and HR in children. Roberson et $a l^{21}$ found that HR was negatively correlated to $\mathrm{S}^{\prime}$ and $\mathrm{E}^{\prime}$ but positively correlated to $\mathrm{A}^{\prime}$, while Eidem et $a l^{18}$ found a negative correlation between all tissue Doppler velocities and HR. Other studies have found positive ${ }^{24}$ correlation between HR and tissue Doppler velocities.

We found a reversed $\mathrm{E}^{\prime} / \mathrm{A}^{\prime}$-relationship in all walls, which has also been shown in earlier studies in premature and term born infants. ${ }^{13}$ Whether this is either because of the immaturity of the myocardium or a sign of diastolic impairment is questionable. However, infants typically have high HRs and this leads to shorter duration of diastole. The start of atrial contraction can thus occur before the completion of the $\mathrm{E}^{\prime}$ wave and be a summation of the remaining $\mathrm{E}^{\prime}$ velocity, which can contribute to a reversed $\mathrm{E}^{\prime} / \mathrm{A}^{\prime}$ relationship. If the atrial contraction occurs before the $\mathrm{E}^{\prime}$ wave reaches its peak, the diastolic wave will be a summation of early ventricular relaxation rate and atrial contraction rate, which will be higher than each of the isolated $\mathrm{E}^{\prime}$ and $\mathrm{A}^{\prime}$ waves.

Table 5 Interobserver and intraobserver variability of the pulsed wave tissue Doppler measurements

\begin{tabular}{|c|c|c|c|c|}
\hline \multirow[b]{2}{*}{ Position } & \multicolumn{2}{|c|}{ Variability (\%) } & \multicolumn{2}{|c|}{$\begin{array}{l}\text { Coefficient of } \\
\text { repeatability } \\
(\mathrm{cm} / \mathrm{s})\end{array}$} \\
\hline & Inter & Intra & Inter & Intra \\
\hline \multicolumn{5}{|c|}{ Left lateral } \\
\hline $\mathrm{S}^{\prime}$ & 5.18 & 4.54 & 0.53 & 0.38 \\
\hline$E^{\prime}$ & 5.68 & 4.02 & 0.70 & 0.56 \\
\hline$A^{\prime}$ & 9.80 & 5.38 & 1.48 & 0.63 \\
\hline \multicolumn{5}{|l|}{ Septum } \\
\hline $\mathrm{S}^{\prime}$ & 5.31 & 4.47 & 0.44 & 0.47 \\
\hline$E^{\prime}$ & 7.07 & 7.76 & 1.06 & 1.16 \\
\hline$A^{\prime}$ & 8.86 & 6.31 & 0.99 & 1.05 \\
\hline \multicolumn{5}{|c|}{ Right lateral } \\
\hline$S^{\prime}$ & 2.98 & 3.08 & 0.38 & 0.40 \\
\hline$E^{\prime}$ & 4.58 & 3.89 & 0.63 & 0.69 \\
\hline$A^{\prime}$ & 2.89 & 3.09 & 0.49 & 0.63 \\
\hline
\end{tabular}


A total fusion of the diastolic pwTDI components is therefore a combined velocity measurement that lacks reference values and should be interpreted with caution. The degree of diastolic fusion should be taken into account when interpreting diastolic velocities.

\section{Strengths and weaknesses}

This study is to our knowledge the first to conduct serial measurements of pwTDI atrioventricular annulus velocities in preterm infants during the transitional newborn period followed by an examination at expected term. The longitudinal design differentiates this study from previous studies on cardiac pwTDI in infants. Extensive changes take place in the haemodynamic situation during the minutes, hours and days after birth. Every examination is a snapshot, but repeated echocardiographic examinations provide valuable insight to a dynamic process. Furthermore, earlier TDI studies in infants have mainly focused on children, term infants or extremely preterm infants. Where moderately preterm infants have been enrolled the studies have been small and with cross-sectional design. So far, there are no studies comparing groups of relatively healthy premature infants to infants with major pathology. Further studies are needed before concluding on the usefulness of TDI in the clinical management. However, this study sheds light on the development of TDI measurements during the first 3 days and after maturation in relatively healthy moderately preterm infants. The study also displays an acceptable reproducibility of the measurements that can provide a basis for further studies.

Limitations to this study include the incompleteness in the number of analyses. This is because of both drop outs at follow-up and poor image-quality in some cases. Image quality was sometimes suboptimal as reflected in the intravariability and the intervariability analyses. The infants were not sedated and some of them were agitated or cried through parts of the examinations, especially during the term examinations. This reflects the difficulties in examining non-cooperative patients, and is also to some extent caused by inevitable biologic variation because of respiration and natural movement. Also, the median age at the first examination was $13 \mathrm{~h}$. Postnatal adaptive changes might already have occurred prior to the first examination. A study design with the first examination after a few minutes or hours after birth and several repeated examinations just a few hours apart could have been more appropriate to detect early postnatal changes in TDI velocities.

In conclusion, serial measurements of TDI velocities in moderately premature infants are feasible with acceptable reproducibility. Gestational age, postnatal age and ventricular size all influenced myocardial function measured by pwTDI velocities. Right ventricle velocities showed more pronounced increase with postnatal maturation than left ventricle velocities. The pwTDI velocities at expected term were higher than those found in earlier studies in term newborns, especially for the right wall and septum. Fusion of diastolic wave components influence diastolic velocities and might obscure comparison between studies. The degree of diastolic fusion should be reported if present.

Author affiliations

${ }^{1}$ Department of Paediatrics, Møre and Romsdal Hospital Trust, Ålesund Hospital, Ålesund, Norway

${ }^{2}$ Department of Circulation and Medical Imaging, Faculty of Medicine, Norwegian University of Science and Technology, Trondheim, Norway

${ }^{3}$ Department of Paediatrics, Vestfold Hospital Trust, Tønsberg, Norway

${ }^{4}$ Department of Medicine, Møre and Romsdal Hospital Trust, Ålesund Hospital, Ålesund, Norway

${ }^{5}$ Faculty of Medicine, Norwegian University of Science and Technology, Trondheim, Norway

${ }^{6}$ Institute of Informatics, University of Oslo, Oslo, Norway

${ }^{7}$ Department of Cardiology, St. Olavs Hospital, Trondheim, Norway

${ }^{8}$ Department of Neonatal Intensive Care, Oslo University Hospital HF, Ullevål,

Oslo, Norway

${ }^{9}$ Faculty of Medicine, Institute of Clinical Medicine, University of Oslo, Oslo, Norway

Acknowledgements Technical and computer-software support have been provided by Jenny Åsmul at GE Vingmed Ultrasound and Einar D Kaarbø and Andreas F Giske from the Medical Technical Department at Ålesund hospital.

Contributors BHE, DF and EN prepared the protocol. BHE and DF acquired the images. BHE analysed the images. TH performed the interrater measurements. $\mathrm{KL}$ and BHE performed the statistics. AS contributed in preparation of the study. All authors contributed in interpreting data, revising drafts of the manuscript and in approval of the final manuscript.

Funding This research received no specific grant from any funding agency in the public, commercial or not-for-profit sectors.

Competing interests None.

Patient consent Obtained.

Ethics approval Regional Committee for Medical and Health Research Ethics, Middle Norway Health Region.

Provenance and peer review Not commissioned; externally peer reviewed.

Data sharing statement No additional data are available.

\section{REFERENCES}

1. Haworth SG. Pulmonary vascular remodeling in neonatal pulmonary hypertension. State of the art. Chest 1988;93:133-8.

2. Fugelseth $\mathrm{D}$, Lindemann $\mathrm{R}$, Liestol $\mathrm{K}$, et al. Ultrasonographic study of ductus venosus in healthy neonates. Arch Dis Child Fetal Neonatal Ed 1997;77:131-4.

3. LeFlore JL, Engle WD. Capillary refill time is an unreliable indicator of cardiovascular status in term neonates. Adv Neonatal Care 2005;5:147-54.

4. Wodey E, Pladys $P$, Betremieux $P$, et al. Capillary refilling time and hemodynamics in neonates: a Doppler echocardiographic evaluation. Crit Care Med 1998;26:1437-40.

5. de Boode WP. Clinical monitoring of systemic hemodynamics in critically ill newborns. Early Hum Dev 2010;86:137-41.

6. Groves AM, Kuschel CA, Knight DB, et al. Relationship between blood pressure and blood flow in newborn preterm infants. Arch Dis Child Fetal Neonatal Ed 2008;93:F29-32.

7. Lopez L, Colan SD, Frommelt PC, et al. Recommendations for quantification methods during the performance of a pediatric echocardiogram: a report from the Pediatric Measurements Writing Group of the American Society of Echocardiography Pediatric and Congenital Heart Disease Council. J Am Soc Echocardiogr 2010;23:465-95; quiz 576-7.

8. Gulati VK, Katz WE, Follansbee WP, et al. Mitral annular descent velocity by tissue Doppler echocardiography as an index of global left ventricular function. Am J Cardiol 1996;77:979-84.

9. Rodriguez L, Garcia M, Ares M, et al. Assessment of mitral annular dynamics during diastole by Doppler tissue imaging: comparison with mitral Doppler inflow in subjects without heart disease and in patients with left ventricular hypertrophy. Am Heart $J$ 1996;131:982-7. 
10. Nagueh SF, Middleton KJ, Kopelen HA, et al. Doppler tissue imaging: a noninvasive technique for evaluation of left ventricular relaxation and estimation of filling pressures. J Am Coll Cardiol 1997:30:1527-33

11. Dalen $\mathrm{H}$, Thorstensen A, Vatten LJ, et al. Reference values and distribution of conventional echocardiographic Doppler measures and longitudinal tissue Doppler velocities in a population free from cardiovascular disease. Circ Cardiovasc Imaging 2010;3:614-22.

12. Mori K, Nakagawa R, Nii M, et al. Pulsed wave Doppler tissue echocardiography assessment of the long axis function of the right and left ventricles during the early neonatal period. Heart 2004:90:175-80.

13. Negrine RJ, Chikermane A, Wright JG, et al. Assessment of myocardial function in neonates using tissue Doppler imaging. Arch Dis Child Fetal Neonatal Ed 2012;97:F304-6.

14. Nestaas E, Stoylen A, Fugelseth D. Optimal types of probe, and tissue Doppler frame rates, for use during tissue Doppler recording and off-line analysis of strain and strain rate in neonates at term. Cardiol Young 2008;18:502-11.

15. Nestaas E, Stoylen A, Sandvik L, et al. Feasibility and reliability of strain and strain rate measurement in neonates by optimizing the analysis parameters settings. Ultrasound Med Biol 2007;33:270-8.

16. Nestaas E, Stoylen A, Brunvand L, et al. Tissue Doppler derived longitudinal strain and strain rate during the first 3 days of life in healthy term neonates. Pediatr Res 2009;65:357-62.
17. Nestaas E, Stoylen A, Brunvand L, et al. Longitudinal strain and strain rate by tissue Doppler are more sensitive indices than fractional shortening for assessing the reduced myocardial function in asphyxiated neonates. Cardiol Young 2011;21:1-7.

18. Eidem BW, McMahon CJ, Cohen RR, et al. Impact of cardiac growth on Doppler tissue imaging velocities: a study in healthy children. J Am Soc Echocardiogr 2004;17:212-21.

19. Bland JM, Altman DG. Statistical methods for assessing agreement between two methods of clinical measurement. Lancet 1986;1:307-10.

20. Joshi S, Edwards JM, Wilson DG, et al. Reproducibility of myocardial velocity and deformation imaging in term and preterm infants. Eur J Echocardiogr 2010;11:44-50.

21. Roberson DA, Cui W, Chen Z, et al. Annular and septal Doppler tissue imaging in children: normal z-score tables and effects of age, heart rate, and body surface area. J Am Soc Echocardiogr 2007;20:1276-84.

22. Sonnenblick EH. Force-velocity relations in mammalian heart muscle. Am J Physiol 1962;202:931-9.

23. Borlaug BA, Melenovsky V, Redfield MM, et al. Impact of arterial load and loading sequence on left ventricular tissue velocities in humans. J Am Coll Cardiol 2007;50:1570-7.

24. Weidemann F, Jamal F, Sutherland GR, et al. Myocardial function defined by strain rate and strain during alterations in inotropic states and heart rate. Am J Physiol Heart Circ Physiol 2002;283:H792-9. 